\title{
Tobacco use and associated mental symptoms and health risk behaviours amongst individuals 15 years or older in South Africa
}

\begin{tabular}{|c|c|}
\hline $\begin{array}{l}\text { Authors: } \\
\text { Karl Peltzer }{ }^{1} \\
\text { Supa Pengpid }\end{array}$ & \\
\hline $\begin{array}{l}\text { Affiliations: } \\
\text { 'Department } \\
\text { Administration } \\
\text { Development, } \\
\text { Limpopo, Turf } \\
\text { South Africa }\end{array}$ & $\begin{array}{l}\text { of Research } \\
\text { and } \\
\text { University of } \\
\text { loop, }\end{array}$ \\
\hline $\begin{array}{l}{ }^{2} \text { ASEAN Institu } \\
\text { Development, } \\
\text { University, Sala } \\
\text { Phutthamonth } \\
\text { Pathom, Thaila }\end{array}$ & $\begin{array}{l}\text { Ite for Health } \\
\text { Mahidol } \\
\text { aya, } \\
\text { lon, Nakhon } \\
\text { and }\end{array}$ \\
\hline $\begin{array}{l}\text { Corresponding } \\
\text { Supa Pengpid, } \\
\text { supaprom @ya }\end{array}$ & g author: \\
\hline $\begin{array}{l}\text { Dates: } \\
\text { Received: 22 D } \\
\text { Accepted: 05 A } \\
\text { Published: } 09 \text { I }\end{array}$ & $\begin{array}{l}\text { ec. } 2019 \\
\text { Aug. } 2020 \\
\text { Nov. } 2020\end{array}$ \\
\hline $\begin{array}{l}\text { How to cite thi } \\
\text { Peltzer K, Peng } \\
\text { use and associ } \\
\text { symptoms and } \\
\text { behaviours am } \\
\text { individuals } 15 \text { ' } \\
\text { in South Africa } \\
\text { Psychiat. 2020; } \\
\text { https://doi.org } \\
\text { sajpsychiatry.v }\end{array}$ & $\begin{array}{l}\text { is article: } \\
\text { spid S. Tobacco } \\
\text { iated mental } \\
\text { health risk } \\
\text { hongst } \\
\text { years or older } \\
\text {. S Afr J } \\
\text {;26(0), a1499. } \\
\text { /10.4102/ } \\
26.10 .1499\end{array}$ \\
\hline $\begin{array}{l}\text { Copyright: } \\
\text { @ 2020. The A } \\
\text { Licensee: AOSI } \\
\text { is licensed und } \\
\text { Creative Comm } \\
\text { Attribution Lice }\end{array}$ & $\begin{array}{l}\text { uthors. } \\
\text { IS. This work } \\
\text { der the } \\
\text { nons } \\
\text { ense. }\end{array}$ \\
\hline Read online: & \\
\hline 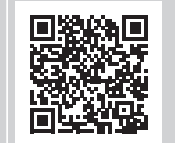 & $\begin{array}{l}\text { Scan this QR } \\
\text { code with your } \\
\text { smart phone or } \\
\text { mobile device } \\
\text { to read online. }\end{array}$ \\
\hline
\end{tabular}

Background: Tobacco use may deteriorate mental health and increase health risk behaviours. Aim: The aim of this investigation was to identify associations between tobacco use and mental illness symptoms and health risk behaviours in individuals 15 years or older in South Africa.

Setting: Community-based national population sample in South Africa.

Methods: Cross-sectional data were analysed from the 'South African National Health and Nutrition Examination Survey (SANHANES-1) 2012', using a sample of 15310 individuals 15 years or older (median age 33 years). Measures included information on tobacco use, sociodemographic factors, mental symptoms and health risk behaviour.

Results: Compared to non-tobacco users, daily tobacco users were associated with psychological distress and post-traumatic stress disorder (PTSD) in adjusted logistic regression analysis, and with sleeping problems in unadjusted analysis. Past tobacco use, less than daily, and daily tobacco use were highly associated with a drinking problem. In terms of dietary variables, less than daily and daily tobacco use increased the odds of inadequate fruit intake and salty food intake, and daily tobacco use decreased the odds of fast food consumption. Past tobacco use, less than daily, and daily tobacco use were inversely associated with physical inactivity, and daily tobacco use was associated with not always washing hands before eating.

Conclusions: The study showed that compared to non-tobacco users, daily tobacco users had significantly poorer mental health (psychological distress and PTSD) and increased odds for several health risk behaviours (drinking problem, inadequate fruit intake, salty food consumption and not always washing hands before eating) as compared to non-tobacco users.

Keywords: mental symptoms; tobacco use; health risk behaviour; post-traumatic stress disorder; South Africa.

\section{Introduction}

'Tobacco kills more than 8 million people each year. Around $80 \%$ of the world's 1.1 billion smokers live in low- and middle-income countries. ${ }^{1}$ Smoking is known to cause various illnesses, including 'cancer, heart disease, stroke, lung diseases, diabetes, and chronic obstructive pulmonary disease (COPD)'. ${ }^{2}$ Fewer studies have linked tobacco use with mental morbidity and health-compromising behaviours.

Some studies found a probable relationship between tobacco use and mental illness, including anxiety and depression in adults..$^{3,4,5,6,7}$ In a systematic review, Kearns et al. ${ }^{8}$ found that:

Smokers were approximately twice more likely to have posttraumatic stress disorder (PTSD) than nonsmokers in the general population, and individuals with PTSD were approximately twice as likely to be current smokers. (p. 1056)

In another systematic review 'high rates of comorbidity of PTSD and tobacco use' were found. ${ }^{9}$ Several cross-sectional studies showed that the prevalence of psychological distress was significantly higher in tobacco users or smokers compared to non-tobacco users or nonsmokers. ${ }^{10,11,12,13}$ Few investigations identified an association between tobacco use and sleep disorder, ${ }^{14}$ poor sleep quality ${ }^{15}$ and short sleep. ${ }^{16}$ Many studies found an association between tobacco use and alcohol consumption, ${ }^{7,17,18,19,20,21}$ hazardous alcohol use ${ }^{15,22}$ and illicit drug use. ${ }^{23}$ 
A number of studies found that compared to non-smokers, smokers had higher odds of having unhealthy nutritional status and dietary behaviour, such as poor diet quality, ${ }^{22,24}$ less compliance with dietary recommendations, ${ }^{24}$ fast-food consumption, ${ }^{21,25}$ more high-fat foods intake, ${ }^{26,27}$ consumption of foods high in sugar and soft drinks, ${ }^{17,21,25,26,28}$ fewer fruit and/or vegetables intake, $17,19,20,21,26,27,28$ high sodium consumption $^{15,19,26}$ and less likely to eat milk and dairy products. ${ }^{21,28}$ In addition, tobacco use was associated with physical inactivity, ${ }^{22,29}$ more exercise, ${ }^{28}$ sedentary behaviour ${ }^{29}$ and poor oral hygiene. ${ }^{15}$

Individuals' habitual participation in a single health-risk behaviour substantially contributes to morbidity and mortality (e.g., tobacco use, daily fast food intake, etc.); however, more concerning is the impact of typically co-occurring or clustering of multiple health-risk behaviours. ${ }^{30}$ (p. 194)

How and if tobacco use is associated with mental illness symptoms and health-compromising behaviours will provide a better understanding on potential relationships across risk behaviours. ${ }^{30}$ This study aimed to identify associations between tobacco use, mental illness symptoms and health risk behaviours in individuals 15 years or older in South Africa.

\section{Method}

\section{Sample and procedure}

The 'South African National Health and Nutrition Examination Survey (SANHANES-1) 2012' is a nationally cross-sectional representative survey of the 'noninstitutionalized population of South Africa' to measure the nutrition and health status of the population. ${ }^{31}$ This survey employed a 'multi-stage disproportionate stratified cluster sampling design' ${ }^{31}$ In all:

500 enumeration areas (EAs) representative of the sociodemographic profile (stratified by province, locality type and race) of South Africa were identified, and a random sample of 20 households was selected from each. EA. ${ }^{31}$ (p. 2)

'All persons residing in the selected households were eligible to participate.' ${ }^{31}$ The current analysis was restricted to persons 15 years and older. Data for this analysis were collected by administering questionnaires to participants (conducting face-to-face interviews). ${ }^{31}$ 'Interviews were conducted by trained fieldworkers. ${ }^{\prime 31}$ The questionnaire was 'translated from English to all national languages and then back translated and pre-tested prior to the main survey' ${ }^{31}$ The individual interview response rate of participants was $92.6 \%{ }^{31}$

\section{Sample size estimation:}

Guided by the requirement of an acceptable precision of estimates per reporting prevalence of a health variable, and the requirement for measuring change over time, the total sample size of 10000 households was based on the minimum sample sizes needed for each reporting health variable, and also took into account the multistage cluster sampling design and the expected response rates. Under the assumption that $75 \%$ of the
10000 households in the sampling frame would agree to participate, the survey would yield 7500 valid contactable households with eligible survey participants. ${ }^{31}$ (p. 45)

\section{Measures}

\section{Outcome variables}

The outcome variables included mental symptoms, substance use and health risk behaviour indicators.

\section{Mental symptoms and substance use indicators}

Psychological distress was measured with the 10-item Kessler scale. ${ }^{32}$ 'This scale inquires about psychological distress symptoms experienced in the past 30 days, with response options ranging from $1=$ never to $5=$ all of the time. '32 'Scores of all items are summed, with scores 20 or more indicating mild, moderate or severe psychological distress. ${ }^{\prime 32}$ The Kessler 10 scale has been 'validated for use in the South African context'33 (Cronbach's alpha 0.93).

Post-traumatic stress disorder was measured with the '17-item Davidson Trauma Scale (DTS)' that assesses 'all primary DSM-IV symptoms of PTSD related to intrusion, avoidance and hyperarousal symptoms' ${ }^{34}$ Participants had preliminary PTSD 'if they score at least one re-experiencing, three avoidance/numbing and two hyperarousal phenomena at a frequency of at least twice in the previous week ${ }^{\prime 34}$ (Cronbach's alpha 0.94). The DTS has not been validated for the South African context. ${ }^{35}$

Sleeping problems were measured with one question on the 'severity of nocturnal sleep problems, such as falling asleep, waking up frequently during the night, or waking up too early in the morning', and one question on the 'severity of difficulty with daytime functioning, not feeling rested and refreshed during the day, for example, feeling tired, not having energy'; responses ranged from ' $0=$ none to $4=$ extreme/cannot do' (Cronbach's alpha 0.82). Sleeping problems were defined as having $4-8$ scores. ${ }^{36}$

Drinking problem or hazardous alcohol use was assessed with the 'Alcohol Use Disorders Identification TestConsumption (AUDIT-C)' ${ }^{37}$

The AUDIT-C has 3 questions and is scored on a scale of $0-12$. Each AUDIT-C question has 5 answer choices valued from 0 points to 4 points. In men, a score of 4 or more is considered positive, optimal for identifying hazardous drinking or active alcohol use disorders. In women, a score of 3 or more is considered positive. ${ }^{37}$ (p. 1091)

(Cronbach's alpha 0.89). The AUDIT-C is a shorter version of the AUDIT-10, which has been validated in South Africa. ${ }^{38,39}$

\section{Health risk behaviour indicators}

Fruit consumption: 'How many fruits do you usually eat per day?' Vegetable consumption: 'How many portions of vegetables, excluding potatoes, do you usually eat per day?'31 
Other dietary items included the consumption of 'Food from fast food outlets (takeaways, for example, pizza, chicken, fish, etc.)?' 'Processed meat, e.g., sausages, polony, cold cuts, Vienna's, Fankfurters, Russians, salami?' 'Snacks, such as chips, crisps, mazimba, etc.?' and 'Sweetened cold drink (gas/fizzy cold drink and reconstituted)?' Responses were classified as 4-6 times in the past week. ${ }^{31}$ In addition, participants were asked, 'Do you prefer to eat your food usually very salty, lightly salted or not salted?'31

Physical activity was measured with the 'General Physical Activity Questionnaire (GPAQ)', ',8,39,40 and grouped into 'low, moderate, and high physical activity' according to GPAQ guidelines. ${ }^{40}$ The GPAQ has been previously validated in nine countries, including in South Africa, and found an acceptable measure of physical activity. ${ }^{41}$

Sedentary behaviour was sourced from the 'time spend sitting or reclining (lying) on a usual weekday or weekend day (excluding sleeping) $)^{\prime 2}{ }^{42}$ and defined as eight or more hours per day. ${ }^{43}$

Not always washing hands before eating was sourced from the question 'How often do you wash your hands before eating?'31

\section{Exposure variable}

Tobacco use was measured with questions on the 'history of tobacco smoking and use of other tobacco products, duration and frequency of use', as follows:

Do you currently smoke tobacco? (Yes, daily; Yes, less than daily; No, not at all) Do you currently use other tobacco products, such as hand-rolled cigarettes, pipes full of tobacco, cigars, cheroots, cigarillos, hookah, hubbly bubbly, water pipe, electronic cigarettes, snuff, chewing tobacco, smokeless tobacco? (Yes, daily; Yes, less than daily; No, not at all). ${ }^{31}$ (p. 9)

\section{Past tobacco use:}

In the past, did you smoke Hand-rolled cigarettes; Pipes full of tobacco; Cigars, cheroots, or cigarillos; Hookah, hubbly bubbly or water pipe sessions; Electronic cigarettes; Any other, specify. In the past, have you used snuff? ...chewing tobacco? ...other smokeless tobacco $?^{31}$ (p. 9)

Based on these questions, participants were divided into never, past, less than daily and daily tobacco users.

\section{Confounding variables}

Demographic data included employment status, population group, sex, age and residence status. ${ }^{31}$

Self-rated health status was assessed with the question: 'In general, how would you rate your health today?'31

Functional disability was assessed with the 12-item 'WHO Disability Assessment Schedule, version 2.0 (WHODAS-II)' ${ }^{44}$ (Cronbach's alpha 0.90) 'The WHODAS-II score was transformed into a score of 0 to 100 , with $25 \%$ or more indicating moderate to extreme functional disability ${ }^{\prime 4}$

Chronic conditions were assessed as follows:

Has a doctor or nurse or health worker at a clinic or hospital told you that you have had any of the following conditions? High blood pressure, stroke, heart disease, heart attack or angina (chest pains), high blood cholesterol, high blood sugar or sugar diabetes. ${ }^{31}$ (p. 381)

\section{Data analysis}

Frequency, median and interquartile range were calculated to describe the sample and its indicators. Unadjusted and adjusted logistic regression using Taylor series linearisation was used to determine the associations between tobacco use categories (never, past, less than daily and daily use) and health outcome variables (mental symptoms and healthcompromising behaviours). The final model was adjusted for relevant confounders, age, sex, population group, employment status, residence status, self-rated health status, chronic conditions and functional disability. The independent variable found to have significant associations with a health outcome variable in the univariate model was used in the multivariable logistic regression model. Missing data were excluded from the calculations. $P<0.5$ was accepted as significant. 'STATA 15.00 (StatCorp LP, College Station, TX)' was used for all statistical analyses, taking into account the weights and clustering effects of the complex sample design.

\section{Ethical consideration}

Informed written consent was obtained from participants. The study protocol was approved by the research ethics committee (REC) of the Human Sciences Research Council (REC 6/16/11/11).

\section{Results}

The sample included 15310 individuals that were 15 years or older (median age of 33 years, interquartile range: $23-47$ years), of which $54.3 \%$ were female, $78.4 \%$ were black African by population group, $63.3 \%$ were employed, $63.4 \%$ lived in urban areas, $22.4 \%$ had a moderate, bad or very bad selfrated health status, $22.8 \%$ had one or more chronic conditions and $9.2 \%$ had a functional disability. Almost one in five participants $(17.2 \%)$ screened positive for psychological distress, $2.1 \%$ for PTSD, $7.1 \%$ for sleeping problems and $20.3 \%$ for drinking problem. More than two in five persons (42.3\%) had fruits less than once in a day, $42.0 \%$ had vegetables less than once in a day, $11.0 \%$ had processed meat frequently ( $\geq 4$ times per week), $15.4 \%$ had snacks frequently ( $\geq 4$ times per week), $10.6 \%$ consumed soft drinks daily, $46.0 \%$ had fast food once or more times in a week and $7.0 \%$ preferred to usually eat their food very salty. Almost half $(47.0 \%)$ of the study population engaged in low physical activity, $13.4 \%$ in sedentary behaviour ( $\geq 8$ hours per day), and $18.2 \%$ did not always wash hands before eating. In all, $77.4 \%$ of participants had never used tobacco, 3.8\% used tobacco in the past, $2.5 \%$ not daily and $16.2 \%$ used tobacco daily. 


\section{Associations with mental symptoms and health- compromising behaviour}

Compared to non-tobacco users, daily tobacco users were associated with psychological distress and PTSD in adjusted logistic regression analysis, and with sleeping problems in unadjusted analysis. Past tobacco use, less than daily, and daily tobacco use were highly associated with drinking problem. In terms of dietary variables, less than daily and daily tobacco use increased the odds of inadequate fruit intake, and daily tobacco use decreased the odds of fast food consumption. Past tobacco use, less than daily, and daily tobacco use were inversely associated with physical inactivity, and daily tobacco use was associated with not always washing hands before eating (see Table 1).

\section{Discussion}

In this large cross-sectional nationally representative study of persons 15 years or older in South Africa, compared to nontobacco users, daily tobacco users had significantly poorer mental health (psychological distress and PTSD) and increased odds for several health-compromising behaviours (drinking problem, inadequate fruit intake, intake of salty food and not always washing hands before eating) as compared to non-tobacco users in adjusted analysis. These findings are largely consistent with previous research. $3,4,5,6,7,10,11,12,15,17,18,19,20,25,26,27$ It is possible that compared to non-tobacco users, 'tobacco users engage to a greater extent in risk denial not only with tobacco use but also with other health risk behaviours' ${ }^{\prime}{ }^{15,26}$

A strong dose-response relationship was found between tobacco use and drinking problem in this study. The high cooccurrence between tobacco and alcohol use is likely to increase with higher rates of consumption of each substance. ${ }^{45,46,47}$ Possible reasons for this heightened cooccurrence risk between tobacco and alcohol use include behavioural, pharmacological and genetic factors. ${ }^{46,47,48}$ The combined use of tobacco and alcohol use is particularly harmful causing increased mortality, ${ }^{49}$ emphasising the need to target both substances in intervention efforts. ${ }^{46,47} \mathrm{~A}$ doseresponse relationship of tobacco use (from never, past, < daily to daily) was in this study identified in other four health indicators (psychological distress, PTSD, poor diet, and poor general hygiene). Similar results were found in a study amongst adolescents ${ }^{21}$ and university students. ${ }^{15}$

Some studies ${ }^{14}$ identified an association between tobacco use and sleep disorder, whilst in this study, this was found in unadjusted analysis. Most studies ${ }^{22,29}$ found an association between tobacco use and physical inactivity and sedentary behaviour, whilst this study found a negative association with physical inactivity and no association with sedentary behaviour. In a study amongst adolescents, tobacco use was also associated with more exercise ${ }^{28}$ and amongst adults in Tunisia, no significant differences were found between male smokers and non-smokers in terms of physical inactivity. ${ }^{26}$
TABLE 1: Associations between tobacco use categories and outcome variables.

\begin{tabular}{|c|c|c|c|c|c|}
\hline Outcome variables & $\begin{array}{l}\text { Tobacco } \\
\text { use }\end{array}$ & UOR & $95 \% \mathrm{Cl}$ & AOR & $95 \% \mathrm{Cl}^{\mathrm{a}}$ \\
\hline \multirow{4}{*}{$\begin{array}{l}\text { Psychological } \\
\text { distress }(17.2 \%)\end{array}$} & Never & 1 & Reference & 1 & Reference \\
\hline & past & 1.61 & $1.20,2.16^{* *}$ & 1.23 & $0.83,1.84$ \\
\hline & $<$ daily & 1.10 & $0.79,1.53$ & 0.96 & $0.66,1.40$ \\
\hline & daily & 1.25 & $1.07,1.47^{* *}$ & 1.49 & $1.22,1.83^{* * *}$ \\
\hline \multirow{4}{*}{$\begin{array}{l}\text { Post-traumatic } \\
\text { stress disorder } \\
(2.1 \%)\end{array}$} & Never & 1 & Reference & 1 & Reference \\
\hline & past & 1.84 & $1.11,3.03 *$ & 1.28 & $0.72,2.28$ \\
\hline & $<$ daily & 2.36 & $1.27,4.38^{* *}$ & 1.82 & $0.79,4.19$ \\
\hline & daily & 1.83 & $1.29,2.58 * * *$ & 1.83 & $1.23,2.71 * *$ \\
\hline \multirow{4}{*}{$\begin{array}{l}\text { Sleeping problems } \\
(7.1 \%)\end{array}$} & Never & 1 & Reference & 1 & Reference \\
\hline & past & 1.93 & $1.34,2.78 * * *$ & 1.09 & $0.68,1.51$ \\
\hline & $<$ daily & 1.40 & $0.91,2.17$ & 1.15 & $0.60,2.19$ \\
\hline & daily & 1.27 & $1.00,1.60 *$ & 1.32 & $0.95,1.83$ \\
\hline \multirow{4}{*}{$\begin{array}{l}\text { Problem drinking } \\
(20.3 \%)\end{array}$} & Never & 1 & Reference & 1 & Reference \\
\hline & past & 2.29 & $1.69,3.20 * * *$ & 2.26 & $1.58,3.23 * * *$ \\
\hline & $<$ daily & 3.94 & $2.83,5.48 * * *$ & 3.23 & $2.23,4.68 * * *$ \\
\hline & daily & 7.15 & $6.23,8.22 * * *$ & 6.00 & $5.09,7.07 * * *$ \\
\hline \multirow{4}{*}{$\begin{array}{l}\text { Fruits }(<1 \text { per day }) \\
(42.3 \%)\end{array}$} & Never & 1 & Reference & 1 & Reference \\
\hline & past & 1.21 & $0.89,1.65$ & 1.37 & $0.96,1.95$ \\
\hline & $<$ daily & 1.49 & $1.13,1.97^{* *}$ & 1.44 & $1.04,2.00 *$ \\
\hline & daily & 1.34 & $1.18,1.53^{* * *}$ & 1.33 & $1.15,1.54 * * *$ \\
\hline \multirow{4}{*}{$\begin{array}{l}\text { Vegetables }(<1 \text { per } \\
\text { day) }(42.0 \%)\end{array}$} & Never & 1 & Reference & - & - \\
\hline & past & 1.14 & $0.86,1.52$ & - & - \\
\hline & $<$ daily & 1.14 & $0.86,1.52$ & - & - \\
\hline & daily & 1.06 & $0.92,1.21$ & - & - \\
\hline \multirow{4}{*}{$\begin{array}{l}\text { Processed meat } \\
\text { ( } \geq 4 \text { times per week) } \\
(11.0 \%)\end{array}$} & Never & 1 & Reference & 1 & Reference \\
\hline & past & 0.55 & $0.33,0.90 *$ & 0.60 & $0.34,1.08$ \\
\hline & $<$ daily & 0.76 & $0.45,1.29$ & 0.77 & $0.41,1.44$ \\
\hline & daily & 0.75 & $0.60,0.94 *$ & 0.80 & $0.62,1.02$ \\
\hline \multirow{4}{*}{$\begin{array}{l}\text { Snacks }(\geq 4 \text { times } \\
\text { per week) }(15.4 \%)\end{array}$} & Never & 1 & Reference & 1 & Reference \\
\hline & past & 0.88 & $0.63,1.23$ & 0.88 & $0.55,1.41$ \\
\hline & $<$ daily & 0.88 & $0.59,1.31$ & 0.99 & $0.65,1.51$ \\
\hline & daily & 0.75 & $0.61,0.92 * *$ & 0.94 & $0.73,1.19$ \\
\hline \multirow{4}{*}{$\begin{array}{l}\text { Soft drink (daily) } \\
(10.6 \%)\end{array}$} & Never & 1 & Reference & - & - \\
\hline & past & 1.23 & $0.64,2.35$ & - & - \\
\hline & $<$ daily & 1.14 & $0.74,1.75$ & - & - \\
\hline & daily & 0.78 & $0.59,1.04$ & - & - \\
\hline \multirow{4}{*}{$\begin{array}{l}\text { Fast food ( } \geq 1 \text { week) } \\
(46.0 \%)\end{array}$} & Never & 1 & Reference & 1 & Reference \\
\hline & past & 0.82 & $0.60,1.12$ & 0.89 & $0.56,1.40$ \\
\hline & $<$ daily & 0.81 & $0.59,1.10$ & 0.85 & $0.62,1.17$ \\
\hline & daily & 0.71 & $0.61,0.83 * * *$ & 0.68 & $0.57,0.81 * * *$ \\
\hline \multirow{4}{*}{$\begin{array}{l}\text { Food very } \\
\text { salty }(7.0 \%)\end{array}$} & Never & 1 & Reference & 1 & Reference \\
\hline & past & 2.00 & $1.39,2.86^{* * *}$ & 1.95 & $1.33,2.85^{* * *}$ \\
\hline & $<$ daily & 2.29 & $1.44,3.65 * * *$ & 1.84 & $1.23,2.77 * *$ \\
\hline & daily & 1.85 & $1.49,2.29 * * *$ & 1.74 & $1.38,2.18 * * *$ \\
\hline \multirow{4}{*}{$\begin{array}{l}\text { Physical activity } \\
\text { (low) }(47.0 \%)\end{array}$} & Never & 1 & Reference & 1 & Reference \\
\hline & past & 0.66 & $0.48,0.90 * * *$ & 0.59 & $0.39,0.90 *$ \\
\hline & $<$ daily & 0.49 & $0.35,0.69 * * *$ & 0.60 & $0.42,0.85^{* *}$ \\
\hline & daily & 0.64 & $0.54,0.76 * * *$ & 0.63 & $0.52,0.76 * * *$ \\
\hline \multirow{4}{*}{$\begin{array}{l}\text { Sedentary ( } 8 \text { or } \\
\text { more hours per day) } \\
(13.4 \%)\end{array}$} & Never & 1 & Reference & - & - \\
\hline & past & 0.74 & $0.45,1.22$ & - & - \\
\hline & $<$ daily & 0.70 & $0.44,1.11$ & - & - \\
\hline & daily & 0.99 & $0.83,1.18$ & - & - \\
\hline \multirow{4}{*}{$\begin{array}{l}\text { Wash hands before } \\
\text { eating (not always) } \\
(18.2 \%)\end{array}$} & Never & 1 & Reference & 1 & Reference \\
\hline & past & 1.25 & $0.83,1.68$ & 1.08 & $0.78,1.51$ \\
\hline & $<$ daily & 1.39 & $1.02,1.90 *$ & 0.92 & $0.64,1.34$ \\
\hline & daily & 1.31 & $1.10,1.55^{* *}$ & 1.30 & $1.07,1.57 * *$ \\
\hline
\end{tabular}

UOR, Unadjusted Odds Ratio; AOR, Adjusted Odds Ratio.

a, Adjusted for age, sex, population group, employment status, residence status, self-rated health status, chronic conditions and functional disability.

***, $p<0.001 ; * *, p<0.01 ; *, p<0.05$. 
Previous studies ${ }^{21,25}$ also found associations between tobacco use and other unhealthy dietary patterns, such as fast-food and soft drink consumption, whilst this study found an inverse association between daily tobacco use and fast-food consumption and no association with soft drink consumption. It is possible that the higher cost of daily tobacco use reduces cash availability to buy fast food. Mathew et al. ${ }^{50}$ have proposed a model for persistent smoking amongst depressive smokers:

$[E] x p e r i e n c i n g$ greater increases in the expected value of smoking in the face of three motivational states (low positive affect, high negative affect and cognitive impairment), which promotes goal-directed choice of smoking behaviour over alternative actions. (p. 401)

Similar mechanisms may be at play with other mental problems, such as anxiety, and possibly health risk behaviours.

The findings of the study support the importance of understanding differences in mental illness symptoms (psychological distress, PTSD symptoms, sleeping problems and drinking problem) and health risk behaviours (such as poor diet, physical inactivity and poor general hygiene behaviour) by tobacco use status for health promoters assisting the general population in making healthy behaviour choices. In addition to tobacco use cessation, tobacco users should be educated about their mental illness symptoms and other health risk behaviours, and that health promotion on healthy diet, well-being, sleep hygiene and other health risk behaviours, such as general hygiene behaviour, should be integrated into tobacco use prevention and control strategies in the general population in South Africa. ${ }^{29}$

\section{The strength and limitations of the study}

The strength of the study was the utilisation of a nationally representative sample of people 15 years and older in South Africa. The major limitation of this study was that it was cross-sectional. Therefore, we were not able to determine the direction of the relationships between tobacco use and mental illness symptoms and health risk behaviours. Further, the measures used were by self-report which may have biased responses.

\section{Conclusion}

In this large cross-sectional national study in South Africa, compared to non-tobacco users, daily tobacco users had significantly poorer mental health (psychological distress and PTSD) and increased odds for several healthcompromising behaviours (drinking problem, inadequate fruit intake, salty food consumption and not always washing hands before eating) as compared to non-tobacco users in adjusted analysis. The found associations may be taken into account in health promotion activities targeting the reduction of tobacco use.

\section{Acknowledgements}

The authors thank the Human Sciences Research Council for the South African National Health and Nutrition Examination Survey (SANHANES-1) 2011-12: Adult Questionnaire - All provinces [Data set].SANHANES2011-12AdultQuestionnaire. Version 1.0. Pretoria South Africa: Human Sciences Research Council [producer] 2012, Human Sciences Research Council [distributor] 2017. http://doi.org/10.14749/1494330158.

\section{Competing interests}

The authors declare that they have no financial or personal relationships that may have inappropriately influenced them in writing this article.

\section{Authors' contributions}

K.P. and S.P. designed and conducted the analyses and wrote the draft article and all authors read and approved the final article.

\section{Funding information}

This research received no specific grant from any funding agency in the public, commercial or not-for-profit sectors.

\section{Data availability statement}

Data of the South African National Health and Nutrition Examination Survey (SANHANES-1) 2011-12 are available at http:/ / datacuration.hsrc.ac.za.

\section{Disclaimer}

The views and opinions expressed in this article are those of the authors and do not necessarily reflect the official policy or position of any affiliated agency of the authors.

\section{References}

1. World Health Organization (WHO) Tobacco factsheet [homepage on the Internet]. 2019 [cited 2019 Dec 12]. Available from: https://www.who.int/news-room/factsheets/detail/tobacco

2. Centers for Disease Control and Prevention (CDC). Smoking and tobacco use: Health effects [homepage on the Internet]. [cited 2019 Dec 12]. Available from: https://www.cdc.gov/tobacco/basic_information/health_effects/index.htm

3. Chaiton MO, Cohen JE, O'Loughlin J, Rehm J. A systematic review of longitudinal studies on the association between depression and smoking in adolescents. BMC Public Health. 2009;9(1):356-367. https://doi.org/10.1186/1471-2458-9-356

4. Fluharty $M$, Taylor AE, Grabski $M$, Munafò MR. The association of cigarette smoking with depression and anxiety: A systematic review. Nicotine Tob Res. 2017;19(1):3-13. https://doi.org/10.1093/ntr/ntw140

5. Prochaska JJ. Smoking and mental illness - Breaking the link. N Engl J Med. 2011;365(3):196-198. https://doi.org/10.1056/NEJMp1105248

6. Peltzer K, Pengpid S. Association between tobacco use and depression and anxiety: A cross-national study among university students from 30 low- and middle-income countries. J Psychol Afr. 2017;27(6):483-487. https://doi.org/ 10.1080/14330237.2017.1347772

7. Nakayama K, Yamaguchi K, Maruyama S, Morimoto K. Association of smoking with other lifestyle factors and mental health status of Japanese factory workers. Environ Health Prev Med. 1997;2(1):11-15. https://doi.org/10.1007/BF02931223

8. Kearns NT, Carl E, Stein AT, et al. Posttraumatic stress disorder and cigarette smoking: A systematic review. Depress Anxiety. 2018;35(11):1056-1072. https:// doi.org/10.1002/da.22828

9. Pericot-Valverde I, Elliott RJ, Miller ME, Tidey JW, Gaalema DE. Posttraumatic stress disorder and tobacco use: A systematic review and meta-analysis. Addict Behav. 2018;84:238-247. https://doi.org/10.1016/j.addbeh.2018.04.024 
10. Islam FMA, Walton A. Tobacco smoking and use of smokeless tobacco and their association with psychological distress and other factors in a rural district in Bangladesh: A cross-sectional study. J Environ Public Health. 2019;2019:1424592. https://doi.org/10.1155/2019/1424592

11. Wang TW, Asman K, Gentzke AS, et al. Tobacco product use among adults - United States, 2017. MMWR Morb Mortal Wkly Rep. 2018;67(44):1225-1232. https:// doi.org/10.15585/mmwr.mm6744a2

12. Hrywna M, Bover Manderski MT, Delnevo CD. Sex differences in the association of psychological distress and tobacco use. Am J Health Behav. 2014;38(4):570-576. https://doi.org/10.5993/AJHB.38.4.10

13. Skov-Ettrup LS, Nordestgaard BG, Petersen CB, Tolstrup JS. Does high tobacco consumption cause psychological distress? A mendelian randomization study. Nicotine Tob Res. 2017;19(1):32-38. https://doi.org/10.1093/ntr/ntw186

14. Hayley AC, Stough C, Downey LA. DSM-5 tobacco use disorder and sleep disturbance: Findings from the National Epidemiologic Survey on Alcohol and Related Conditions-III (NESARC-III). Subst Use Misuse. 2017;52(14):1859-1870. https://doi.org/10.1080/10826084.2017.1316508

15. Pengpid S, Peltzer K. Tobacco use and associated health risk behaviours among university students in 27 countries. Int J Adolesc Med Health. 2020. https://doi. org/10.1515/ijamh-2019-0268

16. Reichenberger DA, Hilmert CJ, Irish LA, Secor-Turner M, Randall BA. Associations between sleep and health-risk behaviors in a rural adolescent population. J Pediat Health Care. 2016;30(4):317-322. https://doi.org/10.1016/j.pedhc.2015.08.003

17. Bottoni A, Cannella C, Del Balzo V. Lifestyle and dietary differences in smokers and non-smokers from an Italian employee population. Public Health 1997;111(3):161-164. https://doi.org/10.1016/S0033-3506(97)00576-3

18. Fujita Y, Maki K. Associations of smoking behavior with lifestyle and mental health among Japanese dental students. BMC Med Educ. 2018:18(1):264. https://doi. org/10.1186/s12909-018-1365-1

19. Kitagawa Y, Nakaji S, Shimoyama T, et al. Differences in lifestyle of a smoking and non-smoking population in Japan. Asian Pac J Cancer Prev. 2000;1(3):245-249.

20. Sonia $\mathrm{H}$, Jihene $\mathrm{M}$, Imed $\mathrm{H}$, et al. Clustering of chronic disease risk factors with tobacco smoking habits among adults in the work place in Sousse, Tunisia. Pan Afr Med J. 2016;24:220. eCollection 2016. https://doi.org/10.11604/pamj.2016.24.220.7163

21. Wang $M$, Wang $H$, Fei FR, Xu CX, Du XF, Zhong JM. The associations between cigarette smoking and health-related behaviors among Chinese school-aged adolescents. Tob Induc Dis. 2017;15:27. eCollection 2017. https://doi.org/10.1186/ s12971-017-0132-0

22. Schumann A, Hapke U, Rumpf HJ, Meyer C, John U. Health behavior of smokers Results of the TACOS (Transitions in Alcohol Consumption and Smoking) study. Gesundheitswesen. 2000;62(5):275-281. https://doi.org/10.1055/s-2000-10975

23. Zammit N, Maatoug J, Ghammam R, Bhiri S, Ghannem H. Tobacco use: The main predictor of illicit substances use among young adolescents in Sousse, Tunisia. In J Adolesc Med Health. 2018. pii: /j/ijamh.ahead-of-print/ijamh-2017-0213/ ijamh-2017-0213.xml. doi: 10.1515/ijamh-2017-0213

24. Alkerwi A, Baydarlioglu B, Sauvageot N, Stranges S, Lemmens P, Shivappa N, Hébert JR. Smoking status is inversely associated with overall diet quality: Findings from the ORISCAV-LUX study. Clin Nutr. 2017;36(5):1275-1282. https://doi. org/10.1016/j.clnu.2016.08.013

25. Larson NI, Story M, Perry CL, Neumark-Sztainer D, Hannan PJ. Are diet and physical activity patterns related to cigarette smoking in adolescents? Findings from Project EAT. Prev Chronic Dis. 2007;4(3):A51.

26. Maatoug J, Harrabi I, Hmad S, Belkacem M, Al'absi M, Lando H, Ghannem H. Clustering of risk factors with smoking habits among adults, Sousse, Tunisia. Prev Chronic Dis. 2013;10:E211. https://doi.org/10.5888/pcd10.130075

27. Woo J, Ho SC, Sham A, Leung SS, Lam TH, Janus ED. Dietary habit of smokers in a Chinese population. Int J Food Sci Nutr. 2001;52(6):477-484. https://doi. org/10.1080/713671805

28. Lee B, Yi Y. Smoking, physical activity, and eating habits among adolescents. West J Nurs Res. 2016;38(1):27-42. https://doi.org/10.1177/0193945914544335

29. Hamadeh RR, Musaiger AO. Lifestyle patterns in smokers and non-smokers in the state of Bahrain. Nicotine Tob Res. 2000;2(1):65-69. https://doi. org/10.1080/14622200050011312

30. Geller K, Lippke S, Nigg CR. Future directions of multiple behaviour change research. J Behav Med. 2017;40(1):194-202. https://doi.org/10.1007/s10865 016-9809-8
31. Shisana O, Labadarios D, Rehle T, et al. South African National Health and Nutrition Examination Survey (SANHANES-1). Cape Town: Human Sciences Research Council Press; 2013.

32. Kessler RC, Andrews G, Colpe LJ, et al. Short screening scales to monitor population prevalences and trends in non-specific psychological distress. Psychol Med. 2002;32(6):959-976. https://doi.org/10.1017/s0033291702006074

33. Andersen LS, Grimsrud A, Myer L, Williams DR, Stein DJ, Seedat S. The psychometric properties of the $\mathrm{K} 10$ and $\mathrm{K} 6$ scales in screening for mood and anxiety disorders in the South African Stress and Health study. Int J Methods Psychiatr Res. 2011;20(4):215-223. https://doi.org/10.1002/mpr.351

34. Davidson JR, Book SW, Colket JT, et al. Assessment of a new self-rating scale for post-traumatic stress disorder. Psychol Med. 1997;27(1):153-160. https://doi. org/10.1017/s0033291796004229

35. Peltzer K, Pengpid S. High physical activity is associated with post-traumatic stress disorder among individuals aged 15 years and older in South Africa. S Afr Psychiatr. 2019;25:1329. doi:10.4102/sajpsychiatry.v25i0.1329

36. Peltzer K, Pengpid S. Prevalence, social and health correlates of insomnia among persons 15 years and older in South Africa. S Afr J Psychol. 2018. https://doi. org/10.1177/0081246318818623

37. Bush K, Kivlahan DR, McDonell MB, Fihn SD, Bradley KA. The audit alcoho consumption questions (AUDIT-C), an effective brief screening test for problem
drinking. Arch Intern Med. 1998;158(16):1789-1795. https://doi.org/10.1001/ drinking. Arch Intern

38. Myer L, Smit J, Roux LL, Parker S, Stein DJ, Seedat S. Common mental disorders among HIV-infected individuals in South Africa: Prevalence, predictors, and validation of brief psychiatric rating scales. AIDS Patient Care STDS. 2008;22(2):147-158. https://doi.org/10.1089/apc.2007.0102

39. Armstrong T, Bull F. Development of the World Health Organization Global Physical Activity Questionnaire (GPAQ). J Pub Health. 2006;14(2):66-70. https:// doi.org/10.1007/s10389-006-0024-x

40. World Health Organization (WHO). Global physical activity surveillance [homepage on the Internet]. 2017 [cited 2017 Dec 02]. Available from: http://www.who.int/ chp/steps/GPAQ/en/index.htm

41. Bull FC, Maslin TS, Armstrong T. Global physical activity questionnaire (GPAQ) Nine country reliability and validity study. J Phys Act Health. 2009;6(6):790-804 https://doi.org/10.1123/jpah.6.6.790

42. Prince SA, LeBlanc AG, Colley RC, Saunders TJ. Measurement of sedentary behaviour in population health surveys: A review and recommendations. PeerJ. 2017;5:e4130. eCollection 2017. https://doi.org/10.7717/peerj.4130

43. Ekelund U, Steene-Johannessen J, Brown WJ, et al. Does physical activity attenuate, or even eliminate, the detrimental association of sitting time with mortality? A harmonised meta-analysis of data from more than 1 million men and women. Lancet. 2016;388(10051):1302-1310. https://doi.org/10.1016/S0140-6736(16)30370-1

44. WHO. Measuring health and disability: Manual for WHO Disability Assessment Schedule (WHODAS 2.0). Ustün T, Kostanjsek N, Chatterji S, Rehm J, editors. Geneva: World Health Organization; 2010.

45. Falk DE, Yi HY, Hiller-Sturmhöfel S. An epidemiologic analysis of co-occurring alcohol and tobacco use and disorders: Findings from the National Epidemiologic Survey on alcohol and related conditions. Alcohol Res Health. 2006;29(3):162-171.

46. Kalman D, Kim S, DiGirolamo G, Smelson D, Ziedonis D. Addressing tobacco use disorder in smokers in early remission from alcohol dependence: The case for integrating smoking cessation services in substance use disorder treatment programs. Clin Psychol Rev. 2010;30(1):12-24. https://doi.org/10.1016/j. cpr.2009.08.009

47. Littleton J, Barron S, Prendergast M, Nixon SJ. Smoking kills (alcoholics)! Shouldn't we do something about it? Alcohol Alcohol. 2007;42(3):167-173. https://doi. org/10.1093/alcalc/agm019

48. Otto JM, Gizer IR, Ellingson JM, Wilhelmsen KC. Genetic variation in the exome: Associations with alcohol and tobacco co-use. Psychol Addict Behav. 2017;31(3):354-366. https://doi.org/10.1037/adb0000270

49. Hart CL, Davey Smith G, Gruer L, Watt GC. The combined effect of smoking tobacco and drinking alcohol on cause-specific mortality: A 30 year cohort study. BMC Public Health. 2010;10:789. https://doi.org/10.1186/1471-2458-10-789

50. Mathew AR, Hogarth L, Leventhal AM, Cook JW, Hitsman B. Cigarette smoking and depression comorbidity: Systematic review and proposed theoretical model. Addiction. 2017;112(3):401-412. https://doi.org/10.1111/add.13604 